\title{
Collaborative Comic-Based Digital Storytelling With Primary School Children
}

\author{
Carolina Beniamina Rutta \\ rutta@fbk.eu \\ University of Trento and FBK \\ Trento, Italy
}

\author{
Massimo Zancanaro \\ University of Trento and FBK \\ Trento, Italy, Italy
}

\author{
Gianluca Schiavo \\ gschiavo@fbk.eu \\ FBK \\ Trento, Italy
}

\author{
Elisa Rubegni \\ University of Lancaster \\ Lancaster, United Kingdom
}

\begin{abstract}
This work explores how comic-based digital storytelling can support primary school children in reflecting on situations involving conflict in the classroom. In particular, we focus on investigating three specific aspects: (1) the potential of digital story composition conducted collaboratively or individually, (2) the children's perception on the use of digital storytelling for reflecting on conflicts that might arise in class and, (3) the teachers' experience of introducing a digital tool for collaborative storytelling and comics composition in an educational context. In this paper, we explored these aspects by developing a case study. A class of 12 children and 2 teachers explore the use of a digital tool, named Communics, aimed at creating digital narratives individually and collaboratively. The results show that digital narratives created from collaborative storytelling are longer, more structured, and richer with meaning compared to stories from individual work. Moreover, it emerged that children prefer to work collaboratively, even if it meant compromising, going slower and waiting for their turn. Finally, teachers appreciated the collaborative use of Communics, and in particular, the turn-based feature as children can practice the narrative re-elaboration with a peer while waiting for their turn.
\end{abstract}

\section{CCS CONCEPTS}

-Human-centered computing $\rightarrow$ Empirical studies in HCI.

\section{KEYWORDS}

Digital Storytelling, Digital Comics, Primary School Children, Educational Context, Technology in Education

ACM Reference Format:

Carolina Beniamina Rutta, Gianluca Schiavo, Massimo Zancanaro, and Elisa Rubegni. 2020. Collaborative Comic-Based Digital Storytelling With Primary School Children. In Interaction Design and Children (IDC '20), Fune 21-24, 2020, London, United Kingdom. ACM, New York, NY, USA, 12 pages. https://doi.org/10.1145/3392063.3394433

\section{INTRODUCTION}

Conflict normally occurs among children, especially at school. Children, for example, may argue about with to sit with during the lessons, which pen to use for taking notes, and when to start or finish a game during the break [47]. On one hand, these kind of conflicts are resolved by the use of physical force, verbal attack, or cold shoulder. On the other hand, conflicts, if properly managed, might be helpful to create and develop a safe educational environment [20]. Yet, children have few outlets through which they can consciously, safely, and attractively reflect on these situations [47]. Therefore, it might be useful to provide support in form of a digital tool for assisting children in facing and reflecting on these situations. In particular, we propose an intervention using digital technology supporting storytelling as a pedagogical approach for facing conflict situations that might take place in the classroom. This approach is aimed at facilitating children in constructing digital narratives, being personalized, compelling, and engaging [30]. Moreover, from the teachers' perspective, digital storytelling should help to engage the whole class, articulating children's thoughts [35], improving communication and promoting a better understanding of each others' perspectives [1]. Specifically, we suggest combining digital storytelling with comics. Comic-based narrations can provide a motivating, fun and engaging genre through which children can meaningfully express themselves by combining graphical and textual elements [29]. Children might 
appreciate the benefits of using comics, which supports the possibility to take different perspectives while remaining engaged in the digital storytelling process [13]. Moreover, in order to support the composition process, we propose the use of a library of graphical and pre-defined textual materials as a scaffolding mechanism [27]. Finally, we propose comparing the composition of both individual and collaborative narratives. Children, in fact, might benefit in reflecting both on their own and in collaboration with peers, and technology can potentially enhance such processes. Our study aims to understand how comic-based digital storytelling can support primary school children in reflecting on situations involving classroom's conflict. Therefore, we have conducted a case study in a primary school, targeting children aged 9 to 10 years old.

\section{RELATED WORK}

In this section, we present a concise overview of the scholarly work in which our research is positioned. In particular, we report works that address the use of (1) digital storytelling in educational context for narrative composition, (2) comics as genre for supporting digital storytelling, and (3) collaborative digital storytelling as practice for reflecting on situations involving conflict.

\section{Digital Storytelling}

Digital storytelling is considered as the process of telling stories using digital tools such as graphics, audio and video. The interest that researchers and educators shows towards digital storytelling for educational is motivated by the potential advantages brought by this medium. In many studies, digital storytelling has been successfully integrated within the school curricula for supporting competencies such as literacy [12], creativity [12, 38], and collaboration [40, 41]. Di Blas and Boretti [12], for example, present a case-study investigating how interactive storytelling can support creativity, media literacy and narration process in preschoolers. Umaschi [50] explores the use of digital storytelling for different school communities, developing a digital storytelling tool for supporting children's exploration of identity and communication issues. Considering older students, Tur and colleagues [24] investigate pedagogical approaches in which digital storytelling can be used for the self-reflection of professional identity. The work of Russel [41] describes ToonTastic, a storytelling tool that empowers young children to compose their own cartoons and share their stories with other children around the world. In view of these benefits, we believe that providing students with digital storytelling might lead to a deeper engagement in the process of story composition and, therefore, it might result in a thoughtful reflection on situations involving classroom's conflict.

\section{Digital comics}

In our research, we combine digital storytelling with comics: a combination of graphical elements and text into an expressive and flexible language to convey sequences of events [25]. In general, comics have been extensively used for meaningfully composing narratives by different communities, such as students [4, 29], children [28], and clinical patients [10, 26]. Considering, in particular, the school context, comics have been used for different purposes such as teaching literacy [46], teaching history [33], and increasing reading comprehension in a foreign language [21]. Its wide use is motivated by the benefits that it can bring, as shown in several works [17, 25, 52-54]. For instance, the study by Yang [54] highlights that comics have the ability to capture and maintain the readers' interests through the graphical elements. Moreover, the combination of graphical and textual elements can promote an emotional connection between the author and the characters in the comics' narrative [52], leading to a deeper immersion in the story composition. Furthermore, the comics layout, having permanent and visual components, in contrast to film and animation, can dictate the pace of the gaze/viewing process $[53,54]$. Still, comics can be beneficial in developing conceptual or logical abilities, such as sequencing and abstract thinking. [17]. In their study, Andrews and Baber [2] show that digital comics can be more goal-oriented than paper-based comics. Bolton [5] argues that different forms of text, such as the one represented by the comics, allow the reader to take a different perspective, intensifying the critical review. In this sense, comic-based digital storytelling might support young students in expressing themselves, being motivated and engaged in the story composition while taking different perspectives.

\section{Digital Storytelling, Collaboration and Conflict}

Many works in the area of Human-Computer Interaction (HCI), and in particular Child-Computer Interaction (CCI), focus on different aspects of collaboration with different purposes, such as, for example, learning programming [7], sharing self-generated representations of algorithms [55], or encouraging guided learning [49]. Digital storytelling, in fact, not only can be beneficial for different aspects such as creativity, motivation and satisfaction, but it can also encourage collaboration [16, 31]. Garzotto and Forfori [14] present FaTe2, a project that combines storytelling, edutainment, and collaboration to promote learning in children, aged 711. Other authors [6] have investigated the use of mobile storytelling applications to allow children to collaboratively create stories combining photos, audio, text and drawings, and to share them online. This study shows that mobile devices can inspire collaborative and creative processes and enrich the storytelling experience. Rubegni and colleagues 
[37, 38] evaluate the impact of a mobile storytelling application, named Fiabot, on educational activities discussing the positive effects of digital storytelling on creativity, digital literacy and collaboration for in-class activities. Other digital tools are introduced in school context for supporting collaborative storytelling with children, as, for example, StoryMat [45], Pogo [34], and Q-Tales [22].

Despite the literature which indicates a strong interest in collaborative practices, few studies $[18,19,48,56,57]$ have investigated the impact of collaborative digital practices in situations involving conflict.

For example, Zancanaro and colleagues [56] investigate the use of multi-user tabletop interfaces to support reconcil-iation of a conflict through the creation of shared narrations. The results demonstrate that the experience with the table-top interface appears to be motivating and, most importantly, produces at least a short-term shift of attitude toward the other. Again, Zancanaro and colleagues [57] present an automated approach to support remote interactions between pairs of participants via storytelling. In this work, the authors focus on the analysis of the automated mediator that supports interactions and helps to achieve positive outcomes. Ioannou and Antoniou [18] explored the use of tabletop as shared interactive spaces as a way to reflect on conflicts. Other works $[19,48]$ discussed more in general technology, such as tabletop, and co-located interface, although none of these studies focused specifically on the use of comic-based digital storytelling for reflecting on conflict in an educational context.

\section{RESEARCH QUESTIONS AND METHODS}

A case study has been conducted in a primary school, target-ing children aged 9 to 10 years, to explore how comic-based storytelling can support primary school students in the task of reflecting on situations involving classroom conflict. A multi-method approach for data collection and analysis was employed, allowing data redundancy and triangulation from multiple perspectives [11].

\section{First research question}

The literature review indicates that digital storytelling can support different skills such as creativity [38], motivation [40], literacy development[12], and collaboration [6, 14, 37, 38, 41, 45]. Many studies have provided evidence that collaborative digital storytelling can be beneficial in provid-ing inspiration [41, 45], in improving performance [6] and in promoting creativity $[6,14,22,34,37,38]$. However, to our knowledge no studies have specifically compared indi-vidual and collaborative digital storytelling for supporting reflection on situations involving conflict among children. Therefore, we conducted a study to explore whether digital storytelling can help children in collaboratively elaborating these situations, and how it might differ from the individual one. Thus, the first research question is:

RQ1. How do children create their narratives for reflecting on situations involving classroom's conflict individually or collaboratively?

In order to address this research question, we compared the narratives produced in collaborative and individual storytelling sessions by analysing their structure, length, valence and meaningfulness. Moreover, we investigated the reported personal experience in performing collaborative or individual storytelling. Semi-structured interviews were conducted to gather information on the storytelling experience. The following questions were addressed to both teachers and children: (a) How was your experience in using the technology individually? (b) How was your experience in using the technology collaboratively?

\section{Second Research Question}

As reported in the literature, digital storytelling is widely recognised for supporting engagement and motivation in the narrative production process [30], especially in young users, and for helping active learning and reflection on reallife situations [51]. However, only few works investigated the use of digital storytelling with digital comics [2, 3, 23], with even less regard to the use of digital comics at school $[2,23]$. In this study, we aim to focus on particular and meaningful aspects of comics for composing educational narratives. specifically, these aspects include the use of pre-defined textual and graphical elements and the introduction to the comics language and to the digital tool. We assume that the pre-defined text can be helpful in inspiring young students in the story composition and in overcoming the blank page syndrome [15]; while the graphical elements can lead them to focus also on the content of the story. Moreover, we consider that children might appreciate the benefits in using comics, which support the possibility to take different perspectives. Finally, we believe that combining comics and technology can represent a promising aspect to support storytelling. This combination, in fact, can enhance the process of reflection and stimulate young students in the story composition. The second research question, therefore, is formulated as follows:

\section{RQ2. How do children experience the use of comic-based digital storytelling for reflecting on situations involving conflict?}

In order to address this research question, we used several methods such as: field notes, short feedback texts, and semistructured interviews conducted with children. The field notes are taken by a researcher during the entire activity. In the short feedback texts, collecting through the support of an 
online web-board ${ }^{1}$, children are asked to write about their experience using the tool. The interview questions focuses on children's experience in using comic-based digital storytelling technology, as follows: (a) Can you describe your experience in using comic-based digital storytelling? (b) What are the positive aspects of using technology and comics for reflecting on situations involving conflict? (c) What are the negative aspects of using technology and comics for reflecting on conflict situations? (d) Did you use the pre-defined textual elements? Why? (e) Did you use graphical elements? Why? (f) What are the differences in using traditional narration and comics?

\section{Third Research Question}

The introduction of technology in the school context is a crucial aspect from both research and educational perspectives. Some works investigated specifically the teachers' perception in using technology, in particular technology for supporting storytelling, in an educational environment [36-38]. However, none of them assessed the specific use of comicbased digital storytelling in the school curricula. Therefore, we decided to investigate teachers' perception in using technology, digital storytelling and comics for supporting students in reflecting on situations involving conflict. Finally, our last research question is the following one:

RQ3. How do teachers experience the use of comic-based digital storytelling for conflict reflection?

To collect data on teachers' experience we used semi-structured interviews. We focused on the following questions: (a) How do you perceived the introduction of technology? How do you think children experienced it? (b) How do you considered the comics use for reflecting on situations involving conflict? How do you think children experienced it? (c) How do you consider children work individually and collaboratively?

\section{COMMUNICS}

In order to answer these research questions we present a case study in which we implemented a didactic activity supported by a digital tool for the creation of storytelling with comics, named Communics. Communics [27, 42-44] is a webbased digital tool for supporting the production of stories in the form of comics combining both graphical and textual elements (Figure 1).

Children can construct digital narratives by choosing graphical elements as backgrounds, characters, and objects from a library. They can add texts either by typing freely or by choosing pre-defined sentences from the library. The predefined sentences have been prepared with the teachers to suggest proper elaboration of specific problematic situations,

\footnotetext{
${ }^{1}$ Padlet, www.padlet.com
}

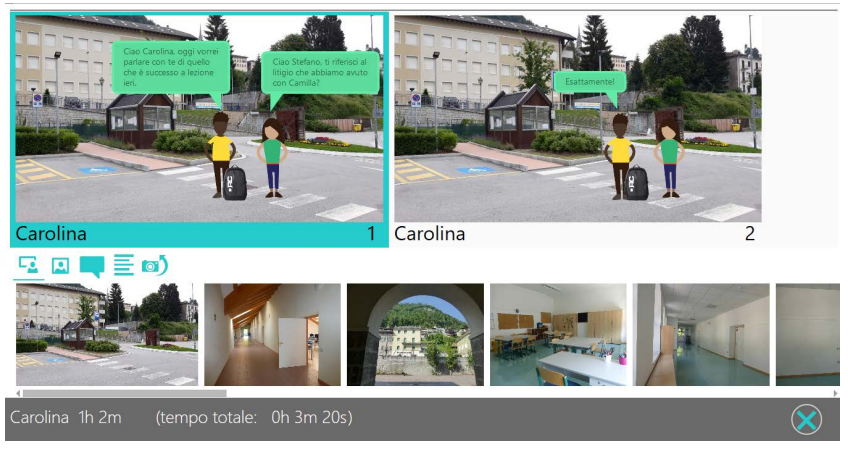

Figure 1: Communics Interface

as explained in the next section. Finally, Communics includes functionalities that allow the creation digital stories individually or collaboratively. In the latter case, children work on different computers and take turns in contributing to the same story.

\section{STUDY SETTING AND DESIGN}

The study was conducted in a primary class of a school named A. De Gasperi, located in Pieve Tesino, near Trento (Italy). A class of 12 children, a first-language teacher and a special needs teacher - the teaching faculty provides for this figure - were involved in the study conducted during the school year 2018-2019.

\section{Stage one: intervention design and content creation process}

Participants. The first-language and special needs teachers.

Procedure. The stage one was structured in two phases:

(1) In order to prepare the intervention, we settled three meetings with the two teachers. At first, we interviewed them to collect information on how to integrate digital comicbased storytelling into school curricula. Then, we discussed children's skills in using technology and in developing narratives, and the specific topic on which to focus the narratives. In general, the teachers were very positive about setting an educational activity to involve children in elaborating situations that involve conflict in the classroom context. One of the major issues reported by the teachers, in fact, was that children do not have ways to deal with situations involving conflict. Therefore, they believe that this approach might be useful for children to reflect on. Finally, working both collaboratively and individually would have give an opportunity to the children for dealing with the situation on their own and with their peers.

(2) The content creation process consisted of two workshops with the teachers to build the graphical and textual elements to be included in Communics's library. The teachers recalled 
situations involving conflict in the classroom in order to define a preliminary list of graphical and textual elements. Eventually, the following conflict situations were chosen for the study:

- children deciding which games to play

- children choosing what to do during lessons breaks

- children discussing the ethical value of a story

- children determining the team leader for a group-work

- children coming to a conclusion for a homework

- children choosing a topic for the lessons

- children composing football teams

- children correcting other children's mistakes

Based on these 8 situations identified by the teachers, a set of materials (backgrounds, characters, pre-defined textual elements and objects) were collected and included in the Communics's library. As background images we selected twentytwo (22) pictures including photos of the school building, the classroom, the computer lab, the school corridor, the school entrance, recreational spaces, and the school garden. Ten (10) images including objects were collected representing elements such as a football ball, a pencil case, and an exercise book. Twelve (12) characters were included representing children and teachers. Finally, forty (40) textual elements were prepared and included. Texts were designed with the aim of helping children to avoid the blank page syndrome and in reflecting on the episodes reported (e.g. "Why did you act in this way?"; "Could you have avoided the conflict somehow?"; "What were the elements that start the conflict?"..."). All the elements of the library were reviewed in order to provide a balanced set of resources to be used as inspiration and as a source of reflection.

\section{Stage two: conducting the educational intervention}

Participants. A classroom of 12 children between 9 and 10 years old $(\mathrm{F}=5, \mathrm{M}=7)$ participated in the intervention.

Procedure. Nine sessions were conducted in a period of 9 weeks. In the first session, children were trained on the use of Communics. One of the researchers explained the Communics interface and children were invited to use the tool both collaboratively (in pairs of two) and individually, in order to allow them to practice in both conditions. In the remaining 8 sessions, children were asked to represent and reflect individually, or collaboratively, on an episode of situations involving conflict in the classroom context. Every week the teachers proposed a different theme for the story, based on the situations discussed in class (according to the 8 scenarios defined). Overall, sessions consisted of a total of 5 collaborative and 3 individual sessions (see Table 1) that produced a total of 63 stories (34 individual and 29 collaborative narratives).

\begin{tabular}{|l|l|l|l|}
\hline Session & Condition & \# Children & \# Stories \\
\hline Pre-session & (Training) & 12 & - \\
1st session & Collaborative & 12 & 6 \\
2nd session & Individual & 10 & 10 \\
3rd session & Collaborative & 12 & 6 \\
4th session & Individual & 12 & 12 \\
5th session & Collaborative & 12 & 6 \\
6th session & Individual & 12 & 12 \\
7th session & Collaborative & 12 & 6 \\
8th session & Collaborative & 9 & 5 \\
\hline
\end{tabular}

Table 1: Conditions, number of children and number of stories divided per sessions

Before each collaborative session, children were grouped in pairs by the teachers. During this phase teachers acted as facilitators. Each session lasted around 1 hour and 30 minutes: 10 minutes for the conflict explanation (using one of the topic defined in stage 1), 1 hour and 20 minutes for the comic creation. Moreover, in the second session and in the third session, 30 minutes were dedicated to individual written feedback on the experience. During the sessions a researcher observed and took notes on the activity.

\section{Stage three: reflection on the study}

Participants. The first-language and the special needs teacher, and 9 children ( 3 of them were absent) participated in this educational stage.

Procedure. Face-to-face semi-structured interviews were conducted with children to gather further information on the storytelling process and to assess its value. Eventually, two face-to-face semi-structured interviews were organized with the two teachers involved in the case study to discuss their experience and assess the feasibility of including comic-based digital storytelling in the school curricula.

\section{DATA ANALYSIS}

Date were analysed on (1) the narratives collected, (2) the children's short feedback texts, interviews and field observations and (3) the teacher's interview.

\section{Narrative analysis}

The narrative analysis was performed on both graphical and textual context, following the thematic analysis [8] approach. The 63 comics - 34 individually and 29 collaboratively - were analysed. Three researchers independently revised the stories and identified different dimensions in the narrative production.

Dimensions were grounded in the theoretical framework of Prince [32] and Bremond's [9] narrative models. The narrative models, in fact, indicate a structure that was used to evaluate the story composition. According to the narrative models, these dimensions consist of: a beginning (1); a middle including a conflict developing (2) and a resolution of 
the conflict (3); and a conclusion (4). In addition to these dimensions, we also explored other narrative's aspects: the Valence of the story, in terms of positive, negative or neutral conflict resolution, and the Meaningfulness of the story, considering whether the story makes sense. Moreover, the Narrative elements such as the number of words balloons and comics' strips, and the time taken for storytelling were considered.

Analysis of the structure of the narrations. For what concerns the collaborative stories, all the 29 stories had a beginning, 27 represented a conflict and in 24 of them the conflict was overcome, 26 reported a conclusion. Regarding the individual stories, 15 out of 34 stories presented a beginning, 15 a rising conflict, 17 a resolution of the conflict, and 14 a conclusion. From this analysis, it emerged that children who did the story in a collaborative way composed stories that generally presented a complete structure. Most narratives include a beginning, a conflict, the overcoming of the conflict and a conclusion. In this sense, it seems that young students collaboratively reflect on the situations involving conflict in most of the narrative composed. Individually, young students compose narratives that, for the greater majority, do not present a complete structure; in this sense, often, young students create a narrative in which they did not present a conflict nor reflect on it.

Valence. Since the task was to produce a narrative presenting a conflict within the classroom and a reflection on the resolution, we performed a valence analysis to assess whether the participant (i) changed the narrative to a positive situation (positive valence), (ii) emphasized the negative aspects of the story increasing the conflict reported (negative valence) or (iii) maintained the pre-existing narration without any clear positive or negative valence (neutral valence). Regarding the collaborative stories, 24 stories reported a resolution of the conflict; 3 a negative valence, while 2 maintained a neutral valence. Considering the individual condition, 15 stories reported a resolution; 17 a neutral valence; while 2 reported a negative valence. It has to be noted that the stories that do not present a conflict were identified as neutral. During the collaborative sessions, it seems that children reflected on the conflict emerged, and presented, most of the time, a positive resolution. In this sense, only 2 stories had a neutral valence. On the contrary, when working individually, most of the stories created do not present a resolution, but narratives without any clear positive or negative valence.

Meaningfulness. Our intention is to discern whether the story created makes sense and has a clear meaning for the researchers. In particular, we indicate a story as meaningful if it includes an appropriate number of images, objects, text, and characters, and if it is coherent with the theme proposed.

\begin{tabular}{|l|l|l|}
\hline Narrative element & Collaborative DS & Individual DS \\
\hline Panel & $11(\mathrm{SD}=6)$ & $6(\mathrm{SD}=2)$ \\
Word Balloon & $20(\mathrm{SD}=10)$ & $12(\mathrm{SD}=4)$ \\
Word Balloon (Child1) & $10(\mathrm{SD}=6)$ & $/$ \\
Word Balloon (Child2) & $12(\mathrm{SD}=8)$ & $/$ \\
Time & $79(\mathrm{SD}=20)$ & $46(\mathrm{SD}=14)$ \\
\hline
\end{tabular}

Table 2: Narrative elements divided per Collaborative and Individual Digital Storytelling composition

Collaboratively, young students compose stories that were mainly meaningful (28), while only 1 story was meaningless. Individually, students proposed 19 meaningful stories and 15 without a clear meaning. This analysis indicates that when working in collaboration with other students generally created stories with clear meaning for as opposed to working individually.

Comic strips analysis. In order to evaluate the formal structure of the comics produced, we analysed the number of panels (i.e. the individual frame that composed a comic strip) and the number of word balloons (i.e. the occurrences of speech or thoughts by a given character in the story) included in the comics. Moreover, in the collaborative narratives, we examine also the single contribution, in terms of word balloons, included by each of the two authors. Finally, the time taken to complete the story was also considered. Regarding the length of the comics, the stories composed in the collaborative condition had on average 11 panels $(\max =30, \min =6, S D=6)$; while individual narrations were shorter with an average of 6 panels $(\max =10, \min =5, S D=2)$. The Mann-Whitney test indicates that the difference is significant $(U=699, p<.01)$. The average number of word balloons included in the collaborative narrations is $20(\max =57, \min =6, \mathrm{SD}=10)$; while in the individual narrative the number decrease with an average of $12(\max =20, \min =3, S D=4)$. Even in this case, the difference is statistically significant $(\mathrm{U}=704, \mathrm{p}<.01)$. Collaboratively, the contribution of each child is generally well balanced: the average number of word balloons insert by the first child that contributes to the story is $10(\mathrm{SD}=6)$, while the peer's number is $12(\mathrm{SD}=8)$. Considering the time taken, young students spent on average 79 minutes in creating comics collaboratively $(\max =114, \min =39, \mathrm{SD}=20)$; while they took on average 46 minutes $(\max =65, \min =19, \mathrm{SD}=14)$ when working individually, thus taking less time compared to collaborative sessions ( $\mathrm{U}=796.5, \mathrm{p}<.01$ ) (see Table 2$)$. In summary, the analyses show that collaborative stories are composed by more panels and words balloons than individual ones, and that participants took longer to create comics in collaborative sessions compared to individual ones. 
Children's short feedback texts, interviews and observation analysis

The data collected for the investigation on children's experience consists of a total of 22 short feedback texts (as 2 young students were absent in the second session) collected in two sessions, 9 interviews (as 3 young students were absent in the last session) and the field notes from observations. The data analysis includes the transcription, and then the coding, using the thematic analysis with a deductive approach [8], among three researchers. At the end of the coding process, the three researchers met up to revise the results collected, and disagreement were revised till researchers came to an agreement.

Comics as a meaningful genre. From the observation, it was noted that children were positively oriented to use this type of narration at school. During the first session, in fact, they were excited in using comics for creating stories during class activities. Moreover, the enthusiasm persisted in the subsequent sessions. In the interviews, eight children expressed their enthusiasm in using digital comics for storytelling. A child said: "I like to use comics because you can express your-self as you like. It is not a traditional school text in which you have to use only words; via comics you can write your story using fewer amount of words. You can also use backgrounds and characters. It's more beautiful than traditional approach because it's really interesting. It is not like a traditional paper-based text which I have to give to the teacher and it is full of grammatical mistakes; here, I can express myself as I want." (P5) One child mentioned that he preferred to use the common narration. He said: "(..) with comics you have to think with your brain because you can lose track of the story, and you don't understand anymore. In traditional books, I used to skip a lot of pages, and I can't do it with comics." (P3)

Pre-defined textual elements. When asked about the pre-defined textual elements, five young students reported to have considered them in their stories. They justify using the pre-defined text for different reasons: for satisfying curiosity, for avoid-ing to write the text, for preventing grammar mistakes, and for inspiring the story composition. One child, for example, said: "I look at the text because it is already written. I do not like to write and I used the pre-defined text." (P3) The remain-ing four young students reported that they did not use the pre-defined text at all. They were all aware of this feature but they actually preferred to write the text on their own, instead of going through the provided list of sentences.

Engagement. From the short feedback texts written by the children, it emerged that, on one hand, they liked working with Communics as it was perceived as fun, engaging, and motivating. In particular, they liked to use technology and to practice a new way for narration in the context of school.
A child reported that he would have liked to train with Communics also at home: "I would like to have Communics also at home; I like it. (P2)" Another child wrote: "Thanks to this software, I discover a new way thorough which I can work. (P1)" In the interviews, it emerged that every young student enjoyed the use of the tool, and appreciated this activity wishing to extend it to other topics as well a child, for example, suggested: "I think that Communics can be used also during the geography or history lessons, maybe not maths. (P6)"

Narrative for reflection. Most of the children (8) evaluated Communics positively. Four young students (4) mentioned that through Communics they could discuss a specific argument with a classmate, and come to an agreement. A child wrote: "The teacher gave us the tool to reflect on specific conflicts that we have during playtime; the teachers let us understand the reasons that lead to the rising of the conflict, and the ways though which we can solve it, and, finally, the methods that can help us in avoiding it; eventually, via comics we can understand our mistakes and we try not to do it again. (P5)"

Content library. As noted in the field observations, several times the teachers were asked to upload new graphical material in Communics to have better variety of content to choose from, for the story composition. Again, in the short feedback texts, they reported that they would have liked to upload their own drawings and different graphical material, in particular new backgrounds and characters. A child wrote: "I would want to have characters that look like me, and other backgrounds. (P6)" Once again, in the interviews, it emerged that young students feel the need to have a greater set of graphical content. Three (3) of them would have liked to have other content uploaded in Communics, mostly characters and backgrounds. A child said: "I wanted more characters as I can represent more people around me, and the story can be more inclusive. (P9)"

Teachers as facilitators. During Communics use, the teachers acted as facilitators and children reported that they were always available when they asked for help. Teachers assisted young students in advancing the story plot, or checking for grammar mistakes. In this sense, teachers were not instructing the students on how to use the digital tool, but they mainly supporting them in structuring the story.

Collaborative and individual narratives. During the collaborative sessions, children did not find difficulties in structuring the plots, while individually the teachers had to assist five out of ten young students in producing their narrative. In the interviews, it emerged 7 young students prefer working collaboratively compared to two students who prefer working individually. On one hand, young students (7) prefer working in pairs as they can create a story with a classmate, alternate in compositing the narrative, compare different 
visions of the story, adb avoiding the possibility of running out of ideas, clearly this is less demanding in terms of effort needed to create a story. On the other hand, they reported that while creating narrative individually, they were more likely to run out of ideas, resulting in the narrative composition which is not challenging enough and, therefrore, tedious. Those young students (2) who prefer creating the narrative individually did not like to compromise with the classmate in structuring the story: resulting in arguments. For these young students, working individually meant being faster, while avoiding compromises.

\section{Teachers interviews' analysis}

The interviews lasted around 30 minutes for each teacher. Transcriptions were analysed using thematic analysis with a deductive approach [8]. Researchers individually examined the interviews. Finally, researchers meet up, review the analysis, and come to an agreement while disagreement emerged. The results are reported below.

Children engagement. Teachers stressed the fact that the young students are "digital natives". For example, a teacher said: "Nowadays students are fed up with pen and paper and traditional learning methods. We always have to look for something new, which is even more similar to their world, and their world includes technology. (T2)" The introduction of technology into school curricula is essential to get young students motivated, engaged and focused during class activities. A teacher said: "If you create a paper-based poster, nobody cares and it remains unused. Using digital tools and new techniques that are different from the traditional ones, instead, means that children are more interested and engaged. They feel as they are actively participating in what they are doing. (T1)"

Teachers and technology. Teachers were positive about introducing technology in their lessons, because young students could understand that technology does not imply only fun, but it can have also an educational purpose. A teacher said: "We have to teach them that these technologies have to be used in a conscious and useful way. (T2)" Moreover, teachers reported that children are used to working on computers, considering traditional digital-based tool for writing (i.e. Word ${ }^{2}$ ), or social media (i.e. Facebook ${ }^{3}$ or Instagram $^{4}$ ), while in this project they learn to examine other tools tailored specifically for the children's education.

Storytelling with comics. Comics were positively perceived by the teachers who regarded them as a genre that can afford the opportunity to identify with a specific character. A

\footnotetext{
${ }^{2}$ www.office.com

${ }^{3}$ www.facebook.com

${ }^{4}$ www.instagram.com
}

teacher said: "In this way, they can live the experience firsthand. (T1)" In this context, young students could benefit from discussing the conflict by focusing on the characters' thoughts instead of spending time describing the situations reported. Through comics, in fact, young students can use backgrounds, characters and objects to represent the physical place of the situation.

Easiness in using Communics. Teachers appreciated the easiness of Communics and the fact that the children did not need extensive training to understand how to use the tool. After the first brief training, participants did not need any further guidance. Teachers also appreciate the innovative features of the tool, that can be used for an educational activity while being engaging and motivating. In this context, Communics represented a way for children to express themselves, interact with each other, create a story, use logical thinking, while reflecting on the conflict episodes. A teacher said: "They can elaborate, and re-elaborate the conflict, and then find the solution that allows them to cooperate. (T1)"

Regulatory effect of the tool. Teachers reported that young students usually work individually during the class hours and that they are not used to collaborate with each other. In the rare case when collaboration activities are settled, the class becomes ungovernable due to the turmoil that young students generated as they are not able to wait for their turn. At the beginning of the study, teachers said that they were attracted by this feature of the tool, as not many didactic digital tools support this practice. In this sense, the turnbased comics creation supported by Communics can support the children in managing the turn-taking, keeping the control when they have to wait their turn to continue the comics. A teacher reported that: "In such a hectic world where they also struggle to raise their hands to express themselves, this becomes a moment in which they know that they have to wait for the other's proposal, possibly re-evaluate it, accept it, or propose something else, so in my opinion it becomes a re-elaboration tool. (T1)". And again: "If I have to build my story on an individual level I organize my ideas and I write down them. With someone to get along, I have to reorganize and do an extra step; that's a skill that is right that emerge at school.

Collaboration. Furthermore, collaboration through Communics could not only encourage young students to understand the turn-taking concept, but also to " (..) learn to coordinate, to respect, and to tell a story."; and again "[Communics] help them in the process to build capacity for dialogue and confrontation. (T1)". Collaboration gives young students the opportunity to work and create a narrative together. In this way, they learn and grow from each other. During the interview, it also emerged how easy and effective it was to learn from 
classmate. A teacher said: "In this case it is not the teacher who intervenes to help the student but it is the other student, and this is doubly advantageous because communication between same-age peers is much simpler and effective than between persons with generational differences". (T2)

Individual sessions. Teachers reported that children enjoyed working individually much more than collaboratively. According to them, while working individually, young students could organize their ideas, and write them down; on the contrary, collaborative storytelling needs compromises, discussion, dialogue and re-elaboration. A teacher said: "Surely in the individual work everyone can express herself freely. Stu-dents are used to working individually, while they have not many occasions to work collaboratively. (T1)"

\section{DISCUSSION}

In this section, the results are discussed considering the three research questions.

\section{RQ1. Collaborative versus individual digital storytelling}

The first question investigates the differences in the use of comic-based digital storytelling while working collaboratively (i.e. in pairs) or individually. From the teachers' point of view, collaboration represents a condition through which children can successfully compose a narrative together with a classmate. While collaborating, young students can come up against, elaborate, and re-elaborate the situation represented, and consequently learn from each other. Moreover, teachers appreciated the turn-based aspect of Communics. This aspect gave the students the opportunity to practice collaboration while working on the same narrative, waiting for the turn while being engaged and motivated by the peer. As it was noted in Rubegni et al. [39], children often come up against problems while collaborating, as it is difficult to establish a turn-taking mechanism in traditional school activities; with a tool like Communics featured with a turnbased mechanism this problem could be overcome. Teachers appreciated also the individual story composition, as young students could still practice with the narrative elaboration, including the development of story path and the dialogue presented. For the teachers, and in general at school, it is important to practice these aspects as they can also determinate the children's abilities needed for their personal and professional future. Finally, during the collaborative activity, young students seem to require less guidance by the teachers. Working collaboratively in pairs, in fact, helped children in generating ideas on the comic plot and structure more easily compared to the individual sessions. In the individual condition, children required further support from the teachers for helping them in structuring the narratives. Considering the young students' opinions, most of them (7) preferred to work in pairs as they could compose a story together with a classmate thus allowing them to alternate the narrative composition, compare different perspectives about the story's plot, avoid the problem of running out of ideas and being less demanding in terms of effort. Only two (2) young students enjoyed creating the narrative individually as they did not like to compromise with the classmate for the story plot. For these young students, working individually meant to work faster, without having to spend time and effort to face discussions for the story's creation.

\section{RQ2. Children's perception}

The second research question concerns the perception of children in practicing digital storytelling and in creating comics for educational purposes to reflect on situations involving conflict. From the field observations, it emerged that young students were positively inclined to use this type of narration at school; even the enthusiasm in using comic-based digital storytelling at school persisted in the subsequent sessions. In the interviews, it emerged that young students would have liked to continue the project as they appreciated the use of Communics for both composing the stories and discussing conflict situations during the class-hours. Every student was familiar with the comics' structure, and found really motivating and engaging working with this genre also at school. In particular, they appreciated to have the possibility to express themselves instead of spending a lot of time on other aspects, such as correcting grammar, or avoiding lexical mistakes. On the other hand, they did not feel completely satisfied in expressing themselves through Communics'library. They reported, in fact, that they would have liked to upload their own drawings and different graphical material, in particular new backgrounds and characters

\section{RQ3. Teachers experience}

Finally, it's our believe that including teachers' considerations in introducing digital storytelling, comics and Communics in their school curricula, is essential. In general, teachers identified many benefits of using technology in class. First of all, teachers stressed the fact that their students are "digital natives", and that the school has to meet the new needs of the children. Secondly, they reported that technology needs to be used also at school to get young students aware that technology does not only imply games. Thirdly, teachers appreciated the easiness in using Communics, as children did not need an extensive training to learn how to use the tool and could focus on the narrative composition. Finally, since children at this age can struggle with conceptual and abstract concepts, teachers reported that young students encountered some difficulties in creating a complete and meaningful plot without their help. However, the use of comics resulted to be 
highly motivating for young students in creating meaningful and significant plot as they can combine both graphical and textual content. Moreover, Communics was indicated by children as an educational tool for understanding the structure of a narrative, including a beginning, middle and end.

\section{CONCLUSION}

This paper presents an empirical study investigating how comic-based storytelling, supported by Communics, can reinforce primary school children in reflecting on conflict situations that might arise in the class. In particular, the study investigates three research questions concerning: (1) the potential of collaborative and individual digital story composition, (2) children' experience in using digital storytelling, and comics for educational purposes for reflecting on situations involving conflict, and (3) teachers' assessment in including the storytelling technology and digital comics in school activities. In order to address the research questions we conducted a case study in an Italian primary class. The study includes a first phase in which the intervention was designed together with the teachers, and both graphical and textual content were created and included in Communics. Secondly, children were invited to compose - individually, or collaboratively - narratives in relation to conflict situations, considering the classroom context. Finally, both teachers and young students were interviewed to understand in greater detail their perception of the experience itself.

In general, the introduction of comic-based digital storytelling in an educational context seems a promising way to encourage young students to reflect on conflicts. A digital tool, such as Communics, can help to support this practice, being engaging and innovative while fully educational. The use of comics as narrative genre was appreciated by the young students, since they had the possibility to take different perspectives while experience "first-hand" situations. In particular, the combination of textual and graphical elements supported the reflective process, although the pre-defined elements were not appreciated by all participants. However, the collaborative creation of stories was perceived as difficult in compromising with the peer but it had also many benefits: fun, engaging and purpose-oriented. On the other hand, during individual storytelling, young students were faster in composing the story, but they run out of ideas more frequently and the teachers' guidance was requested more frequently. Finally, it seems that young students did not reflect on the conflict during the individual activity as much as they did when working in collaboration. In the individual activity the stories, in fact, were less structured, and less meaningful. While the conflict represented, it was not always resolved (as shown in the Narrative analysis and Valence subsections).
The study provides a first contribution in investigating the collaborative use of comic-based digital storytelling in classroom activities, pointing out the added values that confrontation and co-narration between young students can bring in the class activity. At the same time, the results indicate the initial barriers implicit in collaborative storytelling and highlight its differences with respect to individual storytelling activities.

\section{LIMITATIONS AND FUTURE WORK}

A limitation of this work is that we focused on a relatively small group of participants and the extension to a wider sample would strength on our research. Therefore, we plan in future studies to include other primary school classes and more teachers to fully understand the implications of comic-based digital storytelling for reflecting on situations involving conflicts. Future investigations should consider also the novelty effect since it was the first time teachers and students were engaged in comic-based storytelling for reflecting on situations involving conflict. In future studies, we can benefit from the involvement of a developmental psychologist who can provide insights or additional scenarios on conflicts in school environment. Relative to the design of the tool, it will be interesting to involve children in the design of the system. Moreover, giving them the possibility of drawing and inserting their own pictures can be important too. Finally, we plan to investigate the use of comic-based digital storytelling for other purposes, such as teaching geography or history, as the children suggested.

\section{SELECTION AND PARTICIPATION OF CHILDREN}

This study was designed and carried out in close collaboration between the teachers and the researchers. Teachers and researchers got in contact after participating in an educational festival. Before collecting any data, the school and the research center involved in the project signed an agreement to cooperate in the study. The school informed parents about the project, making it clear that participation was voluntary and that all data would remain confidential. Children were told about the aims of the study by the teachers and the researchers. The activity described in this paper took place in the computer lab of the school. Teachers acted as facilitators, ensuring that children did not feel under any pressure during the study.

\section{ACKNOWLEDGMENTS}

We would like to thank Alex, Danya and Stefano for their help. 


\section{REFERENCES}

[1] Halah Ahmed Alismail. 2015. Integrate Digital Storytelling in Education. Journal of Education and Practice 6, 9 (2015), 126-129.

[2] Daniel Andrews and Chris Baber. 2014. Visualizing interactive narratives: employing a branching comic to tell a story and show its readings. In Proceedings of the SIGCHI Conference on Human Factors in Computing Systems. ACM, 1895-1904.

[3] Daniel Andrews, Chris Baber, Sergey Efremov, and Mikhail Komarov. 2012. Creating and using interactive narratives: reading and writing branching comics. In Proceedings of the SIGCHI Conference on Human Factors in Computing Systems. ACM, 1703-1712.

[4] Michael Bitz. 2004. The comic book project: Forging alternative pathways to literacy. Journal of Adolescent \& Adult Literacy 47, 7 (2004), 574-586.

[5] Gillie Bolton. 2011. Write yourself: Creative writing and personal development. Jessica Kingsley Publishers.

[6] Elizabeth Bonsignore, Alexander J Quinn, Allison Druin, and Benjamin B Bederson. 2013. Sharing stories "in the wild": A mobile storytelling case study using StoryKit. ACM Transactions on ComputerHuman Interaction (TOCHI) 20, 3 (2013), 18.

[7] Grant Braught, Tim Wahls, and L Marlin Eby. 2011. The case for pair programming in the computer science classroom. ACM Transactions on Computing Education (TOCE) 11, 1 (2011), 2.

[8] Virginia Braun and Victoria Clarke. 2006. Using thematic analysis in psychology. Qualitative research in psychology 3, 2 (2006), 77-101.

[9] Claude Bremond. 1966. La logique des possibles narratifs. Communications 8, 1 (1966), 60-76.

[10] MK Czerwiec and Michelle N Huang. 2017. Hospice comics: representations of patient and family experience of illness and death in graphic novels. Fournal of Medical Humanities 38, 2 (2017), 95-113.

[11] Norman K Denzin and Yvonna S Lincoln. 2011. The Sage handbook of qualitative research. Sage.

[12] Nicoletta Di Blas and Bianca Boretti. 2009. Interactive storytelling in pre-school: a case-study. In Proceedings of the 8th International conference on interaction design and children. ACM, 44-51.

[13] Matteo Farinella. 2018. The potential of comics in science communication. Fournal of science communication 17, 1 (2018), Y01.

[14] Franca Garzotto and Matteo Forfori. 2006. FaTe2: storytelling edutainment experiences in 2D and 3D collaborative spaces. In Proceedings of the 2006 conference on Interaction design and children. ACM, 113-116.

[15] Jenna Glatzer. 2003. Outwitting Writer's Block: And Other Problems of the Pen. Globe Pequot.

[16] Timo Göttel. 2011. Reviewing children's collaboration practices in storytelling environments. In Proceedings of the 10th International Conference on Interaction Design and Children. ACM, 153-156.

[17] Phyllis N Hallenbeck. 1976. Remediating with comic strips. Journal of learning disabilities 9, 1 (1976), 11-15.

[18] Andri Ioannou and Chrystalla Antoniou. 2016. Tabletops for peace: technology enhanced peacemaking in school contexts. fournal of Educational Technology \& Society 19, 2 (2016), 164-176.

[19] Andri Ioannou, Panayiotis Zaphiris, Fernando Loizides, and Christina Vasiliou. 2013. Let's talk about technology for peace: A systematic assessment of problem-based group collaboration around an interactive tabletop. Interacting with Computers 27, 2 (2013), 120-132.

[20] David W Johnson, Roger T Johnson, and Edythe Johnson Holubec 1994. The nuts and bolts of cooperative learning. Interaction Book Co.

[21] Jun Liu. 2004. Effects of comic strips on L2 learners' reading comprehension. TESOL quarterly 38, 2 (2004), 225-243.

[22] Bonnie Thompson Long, Tony Hall, Michael Hogan, Owen Harney, Theodoros Doukoulos, and Chita Murray. 2017. Using a Collective
Intelligence Scenario-Based Design approach to develop a collaboration ecosystem supporting the authorship of pedagogically valuable e-books for children. Journal of Literacy and Technology 18, 2 (2017).

[23] Nancy Maldonado and Ting Yuan. 2011. Technology in the classroom: from Ponyo to "My Garfield Story": using digital comics as an alternative pathway to literary composition. Childhood Education 87, 4 (2011), 297-301.

[24] Victoria I Marín, Gemma Tur, and Jane Challinor. 2018. An interdisciplinary approach to the development of professional identity through digital storytelling in health and social care and teacher education. Social Work Education 37, 3 (2018), 396-412.

[25] Scott McCloud. 1993. Understanding comics: The invisible art. Northampton, Mass (1993).

[26] Sarah McNicol. 2017. The potential of educational comics as a health information medium. Health Information \& Libraries fournal 34, 1 (2017), 20-31.

[27] Eleonora Mencarini, Gianluca Schiavo, Alessandro Cappelletti, Oliviero Stock, and Massimo Zancanaro. 2015. Assessing a collaborative application for comic strips composition. In IFIP Conference on Human-Computer Interaction. Springer, 73-80.

[28] Timothy G Morrison, Gregory Bryan, and George W Chilcoat. 2002. Using student-generated comic books in the classroom. Fournal of Adolescent \& Adult Literacy 45, 8 (2002), 758-767.

[29] Bonny Norton. 2003. The motivating power of comic books: Insights from Archie comic readers. The Reading Teacher 57, 2 (2003), 140-147.

[30] Jason B Ohler. 2013. Digital storytelling in the classroom: New media pathways to literacy, learning, and creativity. Corwin Press.

[31] Howard J Pitler. 2006. Viewing technology through three lenses. PRINCIPAL-ARLINGTON- 85, 5 (2006), 38.

[32] Gerald Prince. 2012. Narratology: The form and functioning of narrative. Vol. 108. Walter de Gruyter.

[33] Livia Carolina Ravelo. 2013. The use of comic strips as a means of teaching history in the EFL class: Proposal of activities based on two historical comic strips adhering to the principles of CLIL. Latin American fournal of Content \& Language Integrated Learning 6, 1 (2013), 1-19.

[34] Antonio Rizzo, Patrizia Marti, Françoise Decortis, Job Rutgers, and Paul Thursfield. 2018. Building narrative experiences for children through real time media manipulation: POGO World. In Funology 2. Springer, 479-492.

[35] Bernard R Robin. 2008. Digital storytelling: A powerful technology tool for the 21st century classroom. Theory into practice 47, 3 (2008), 220-228.

[36] Elisa Rubegni and Monica Landoni. 2013. Modelling the role of teachers in introducing portable technology to the school curriculum. In Proceedings of the 31st European Conference on Cognitive Ergonomics. ACM, 13.

[37] Elisa Rubegni and Monica Landoni. 2014. Fiabot!: design and evaluation of a mobile storytelling application for schools. In Proceedings of the 2014 conference on Interaction design and children. ACM, 165-174.

[38] Elisa Rubegni and Monica Landoni. 2015. Supporting creativity in designing story authoring tools. In Proceedings of the 14th International Conference on Interaction Design and Children. ACM, 287-290.

[39] Elisa Rubegni, Monica Landoni, Antonella De Angeli, and Maria Letizia Jaccheri. 2019. Detecting Gender Stereotypes in Children Digital StoryTelling. In Proceedings of the 18th ACM International Conference on Interaction Design and Children. Association for Computing Machinery, ACM.

[40] Elisa Rubegni and Paolo Paolini. 2010. Comparing canonical and digital-based narrative activities in a formal educational setting. In Proceedings of the 9th International Conference on Interaction Design and Children. ACM, 258-261. 
[41] Andy Russell. 2010. ToonTastic: a global storytelling network for kids, by kids. In Proceedings of the fourth international conference on Tangible, embedded, and embodied interaction. ACM, 271-274.

[42] Carolina Beniamina Rutta, Gianluca Schiavo, and Massimo Zancanaro. 2018. Interactive Comic-Based Digital Storytelling for Self-expression. In International Conference on Interactive Digital Storytelling. Springer, 657-661.

[43] Carolina Beniamina Rutta, Gianluca Schiavo, and Massimo Zancanaro. 2019. Comic-based Digital Storytelling for Self-expression: an Exploratory Case-Study with Migrants. In Proceedings of the 9th International Conference on Communities \& Technologies-Transforming Communities. ACM, 9-13.

[44] Carolina Beniamina Rutta, Gianluca Schiavo, Massimo Zancanaro, Elisa Rubegni, et al. 2019. Comic-based Digital Storytelling with Primary School Children. (2019).

[45] Kimiko Ryokai and Justine Cassell. 1999. StoryMat: A Play Space with Narrative Memories.. In IUI. 201.

[46] Gretchen E Schwarz. 2002. Graphic novels for multiple literacies. Journal of adolescent and adult literacy 46, 3 (2002), 262-265.

[47] Laurie Stevahn, Linda Munger, and Kathy Kealey. 2005. Conflict resolution in a French immersion elementary school. The fournal of Educational Research 99, 1 (2005), 3-18.

[48] Oliviero Stock, Massimo Zancanaro, Chaya Koren, Cesare Rocchi, Zvi Eisikovits, Dina Goren-Bar, Daniel Tomasini, and Patrice Tamar Weiss. 2008. A co-located interface for narration to support reconciliation in a conflict: initial results from Jewish and Palestinian youth. In Proceedings of the SIGCHI Conference on Human Factors in Computing Systems. ACM, 1583-1592.

[49] Jennifer Thom-Santelli, Kirsten Boehner, Geri Gay, and Helene Hembrooke. 2006. Beyond just the facts: transforming the museum learning experience. In CHI'06 extended abstracts on Human factors in computing systems. ACM, 1433-1438.

[50] Marina Umaschi. 1996. Sage storytellers: Learning about identity, language and technology. In Proceedings of the 1996 international conference on Learning sciences. International Society of the Learning Sciences, 526-531.

[51] Frank Van Gils. 2005. Potential applications of digital storytelling in education. In 3rd twente student conference on IT, Vol. 7. University of Twente, Faculty of Electrical Engineering, Mathematics and ....

[52] Rocco Versaci. 2001. How comic books can change the way our students see literature: One teacher's perspective. The English fournal 91, 2 (2001), 61-67.

[53] Neil Williams. 1995. The comic book as course book: Why and how. (1995).

[54] Gene Yang. 2003. Strengths of comics in education. Comics in Education (2003).

[55] Teresa Hübscher Younger. 2000. Understanding algorithms through shared metaphors. In CHI'00 Extended Abstracts on Human Factors in Computing Systems. ACM, 83-84.

[56] Massimo Zancanaro, Oliviero Stock, Zvi Eisikovits, Chaya Koren, and Patrice L Weiss. 2012. Co-narrating a conflict: an interactive tabletop to facilitate attitudinal shifts. ACM Transactions on Computer-Human Interaction (TOCHI) 19, 3 (2012), 24.

[57] Massimo Zancanaro, Oliviero Stock, Gianluca Schiavo, Alessandro Cappelletti, Sebastian Gehrmann, Daphna Canetti, Ohad Shaked, Shani Fachter, Rachel Yifat, Ravit Mimran, et al. 2019. Evaluating an automated mediator for joint narratives in a conflict situation. Behaviour \& Information Technology (2019), 1-16. 